\title{
BALANCED SCORECARD COMO SUPORTE ÀS DECISÕES GERENCIAIS: ESTUDO DE CASO EM UMA PROPRIEDADE LEITEIRA DE MÉDIO PORTE
}

\author{
LOPES, Marcos Aurélio ${ }^{1}$ \\ CARDOSO, Antônio Augusto Brion ${ }^{2}$ \\ CARVALHO, Francisval de $\mathrm{Melo}^{3}$ \\ FERRAZZA, Rodrigo Andrade ${ }^{4}$ \\ LIMA, André Luís Ribeiro ${ }^{3}$ \\ CARDOSO, Milton Ghedini ${ }^{5}$
}

RESUMO: Objetivou-se analisar a aplicabilidade do Balanced Scorecard (BSC) em uma propriedade produtora de leite com média escala de produção, localizada no sul de Minas Gerais (MG). A pesquisa foi realizada nos meses de janeiro a dezembro de 2013. O levantamento das informações foi realizado por meio de entrevistas semiestruturadas realizadas in loco. Como instrumentos de coleta de dados foram utilizados a entrevista pessoal, a análise documental e a observação direta e participante. A fazenda possui 396 ha, onde $40 \%$ desta área é alugada. As atividades desenvolvidas são a pecuária leiteira, que corresponde a $60 \%$ do faturamento, e o cultivo do café, com $40 \%$. O plantel da fazenda é de 164 vacas da raça holandesa, puras por cruzamento ou puras por origem (PC ou PO) que ficam semi-confinadas. A produção média diária é de $3.200 \mathrm{~kg}$, média de 19,51 litros de leite por vaca em lactação, em duas ordenhas diárias. Os pontos fortes são a localização, infraestrutura e fonte própria de água; enquanto que os pontos fracos foram, mão de obra, falta de controle e gestão realizada de forma reativa. A missão criada leva em consideração a implantação de melhorias no que diz respeito à gestão, para se alcançar a qualidade dos produtos e dos recursos humanos. Foi proposto um mapa estratégico, onde é possível perceber que os objetivos, crescimento e inovação serão alcançados levando em consideração o aumento da receita. Foi verificado, ao final do estudo, que os princípios do $B S C$ podem ser aplicados a uma propriedade produtora de leite de médio porte.

Palavras-chave: BSC. Planejamento estratégico. Pecuária leiteira. Escala de produção.

SUMMARY: The objective was to analyze the applicability of the Balanced Scorecard (BSC ) in a dairy farm with average production scale, located in the south of Minas Gerais. The survey was conducted from January to December 2013. The survey information was conducted through semi-structured interviews on the spot. As data collection instruments were used the personal interview, document analysis and direct and participant observation. The farm has 396 there, where $40 \%$ of this area is rented. The activities are dairy farming, which accounts for $60 \%$ of sales, and the coffee cultivation, with $40 \%$. The breeding farm is 164 Holstein cows, pure by crossing or by pure source (PC or PO) that are semi-confined. The average daily production is $3.200 \mathrm{~kg}$, average of 19.51 liters of milk per cow in milk, in two daily milkings. The strong points are the location, infrastructure and own water source; while the weaknesses were, manpower, lack of control and reactively management performed. The mission created taking into account the implementation of improvements with regard to the management, to achieve product quality and human resources. A strategic map where you can see that the objectives, growth and innovation will be achieved taking into account the increase in revenue was proposed. It was found at the end of the study, that the principles of BSC can be applied to a producing midsize milk.

Keywords: BSC. Strategic planning. Dairy farming. Production scale.

\footnotetext{
${ }^{1}$ Professor titular do departamento de medicina veterinária da Universidade Federal de Lavras - UFLA

${ }^{2}$ Mestre em Administração pela UFLA, professor efetivo do Departamento de Ciências Contábeis da UFJF Campus Governador Valadares

${ }^{3}$ Doutor em Administração e professor do departamento de Economia e Administração da Universidade Federal de Lavras - UFLA

${ }^{4}$ Doutorando em Medicina Veterinária - UNESP

${ }^{5}$ Mestre em Medicina Veterinária - UFLA
} 
RESUMEN: Este estudio tuvo como objetivo analizar la aplicabilidad del cuadro de mando integral (BSC) en una granja de productos lácteos con la escala de producción media, situado en el sur de Minas Gerais. La encuesta se llevó a cabo de enero a diciembre de 2013. La información de la encuesta se llevó a cabo a través de entrevistas semiestructuradas sobre el terreno. A medida que se utilizaron instrumentos de recolección de datos de entrevistas personales, análisis de documentos y observación directa y participante. La finca cuenta con 396 hectáreas, donde se alquila el $40 \%$ de esta superficie. Las actividades son la ganadería lechera, que corresponde al $60 \%$ de los ingresos, y el cultivo de café, con un 40\%. La granja de cría es de 164 vacas Holstein puras, por el cruce o por fuente pura (PC o PO) que son semi-confinado. La producción media diaria es de $3.200 \mathrm{~kg}$, promedio de 19,51 litros de leche por vaca en la leche, en dos ordeños diarios. Los puntos fuertes son la ubicación, la infraestructura y la propia fuente de agua; mientras que las debilidades eran, mano de obra, la falta de control y gestión reactiva a cabo. La misión creada tiene en cuenta la implementación de mejoras en cuanto a la gestión, para lograr la calidad del producto y los recursos humanos. Se propuso un mapa estratégico donde se puede ver que se alcanzarán los objetivos, el crecimiento y la innovación teniendo en cuenta el aumento de los ingresos. Se encontró, al final del estudio, que los principios de BSC se pueden aplicar a una leche de tamaño medio propiedad de la compañía de producción.

Palabras clave: BSC. La planificación estratégica. La ganadería lechera. La escala de producción.

\section{INTRODUÇÃO}

Profundas transformações têm marcado a pecuária leiteira no Brasil nos últimos anos. Além das mudanças de caráter econômico, outras questões têm desafiado o setor primário brasileiro. Esse contexto tem exigido um nível de profissionalismo nunca antes experimentado. Porém, infelizmente, essas mesmas transformações expuseram, de forma mais clara, a fragilidade que alguns pontos da cadeia produtiva agroindustrial possuem em termos de gestão eficiente da organização e isso tem sido um grande entrave para o desenvolvimento desse setor.

Para Phillips e Peterson (1999) e Oiagen et al. (2008), a adoção das funções administrativas de planejamento, organização, direção e controle, por parte dos produtores rurais, podem contribuir positivamente para melhorar o resultado econômico das unidades de produção rural. Apesar dessa provável associação positiva entre o uso de técnicas de gerenciamento e o sucesso econômico das empresas rurais, tem-se observado que a maioria das fazendas brasileiras ainda não adota as várias técnicas já consagradas de administração (CANZIANI, 2001; GODINHO et al., 2014).

Rocha e Leite (2007) afirmaram que o agronegócio há muitos anos vem usando, como base da gestão, apenas os resultados financeiros, deixando de lado funções importantes como o planejamento e controle. Diante da importância desse tema, Kaplan e Norton (1997) enfatizaram a necessidade de incorporar aos modelos de indicadores financeiros tradicionais outros indicadores não-financeiros, como satisfação e retenção dos clientes, motivação dos funcionários, como forma de aperfeiçoamento dos processos internos.

Neste sentido, o BSC (Balanced Scorecard) tem se mostrado uma ferramenta útil para auxiliar empresas de diferentes setores a tornarem-se mais competitivas, pois busca incorporar aos indicadores financeiros tradicionais, os indicadores não-financeiros e, com isso, melhorar a avaliação de desempenho das organizações. Na literatura internacional são descritas algumas abordagens para a gestão e utilização do BSC em empresas do agronegócio. Pesquisas envolvendo o BSC foram identificadas na Noruega (NOELL;LUND, 2002), Irlanda (BYRNE; KELLY, 2004), Nova Zelândia (JACK, 2009; CARDEMILKATUNARIC; SHADBOLT, 2006), Ucrânia (LISSITSA, 2005) e EUA (DUNN et al., 2006; SHADBOLT, 2007 ; DUNN; ETHEREDGE , 2005). O BSC foi aplicado a vários setores agrícolas, incluindo o leite, pecuária de corte e fruticultura. Ele também foi introduzido para a cadeia de produção de carne na Austrália (BRYCESON; SLAUGHTER, 2010) e para a cadeia de abastecimento alimentar na Itália (BIGLIARDI; BOTTANI, 2010). 
O fato é que, no Brasil, muitos empresários rurais não têm conseguido gerir seus empreendimentos com a agilidade e a eficiência necessárias para mantê-los em situação competitiva. Considerando a relevância do tema, bem como a escassez de artigos científicos sobre o assunto, apresenta-se este estudo diante da seguinte problemática: como adaptar os princípios do Balanced Scorecard a uma propriedade produtora de leite de porte médio com intuito de aumentar a eficiência do seu sistema de gestão? Com base nisso objetivou-se analisar a aplicabilidade do Balanced Scorecard (BSC) em uma propriedade produtora de leite com média escala de produção, localizada no sul de Minas Gerais (MG). Especificamente, pretendeu-se desenvolver um modelo de indicadores de desempenho, com base no BSC, e propor um painel de indicadores estratégicos, utilizando seus princípios, visando estimular o processo de medição de desempenho, fornecendo suporte às decisões gerenciais e apoiando a melhoria contínua na pecuária leiteira.

\section{MATERIAL E MÉTODO}

A pesquisa caracteriza-se como exploratória quanto aos objetivos (SALOMON, 1999) e, de caráter qualitativo (BRYMAN, 1989; SPECTOR, 2002), quanto à natureza. Especificamente um estudo de caso (TRIVIÑOS, 1987; YIN, 1981; YIN, 2013).

A escolha da região sul do Estado de Minas Gerais é justificada pela sua tradição e importância enquanto bacia leiteira. Já a unidade de análise foi escolhida levando-se em consideração os seguintes critérios: disponibilidade do proprietário para participar da pesquisa, bem como seu interesse na realização da mesma e facilidade de acesso por parte dos pesquisadores às fontes de evidências.

A partir do conhecimento da teoria relacionada ao BSC, se determinou uma sequência lógica de estruturação e proposição da ferramenta à empresa objeto deste estudo. A pesquisa qualitativa foi desenvolvida visando à proposição de um painel de indicadores de medição de desempenho, baseado na metodologia do BSC.

A execução do trabalho teve como base a interação entre os pesquisadores e a gestora (proprietária) para quem se fez a apresentação do projeto na íntegra, com o objetivo de informá-la de toda a metodologia. Houve também uma interação entre os pesquisadores e os colaboradores com intuito de motivar o grupo para a aplicação do método.

Como instrumentos de coleta de evidências foram utilizados a entrevista semiestruturada (TRIVIÑOS, 1987), por meio de um formulário semiestruturado que mescla questões de caráter qualitativo e quantitativo, que foi desenvolvido com o objetivo de coletar informações para a elaboração de um levantamento minucioso de dados e informações direcionadas à composição de uma visão geral e avaliação dos fatores críticos de sucesso da empresa. Esse formulário foi dividido em quatro partes e todas elas respondidas pela proprietária. A primeira parte é referente a caracterização da propriedade, tamanho, estrutura física, atividades, quantidade de funcionários entre outras. A segunda parte refere-se ao rebanho e a produção do leite, qual o tamanho, a raça, a quantidade e o tipo de leite produzido. A terceira diz respeito a gestão da propriedade, a gestão financeira, gestão de pessoas e gestão comercial. A quarta e última leva em consideração a parte estratégica da propriedade. Devido a extensão do questionário, sua aplicação foi dividida em quatro dias e as respostas foram gravadas e posteriormente transcritas na íntegra, o que possibilitou uma análise de conteúdo mais apurada.

Fizeram parte também da pesquisa, a análise documental e a observação direta e participante. $\mathrm{O}$ exame de documentos permitiu complementar as demais técnicas e verificar a validade dos dados, além de permitir acesso a outras informações. A observação direta e participativa permitiu ainda aprimorar o conhecimento do comportamento e da comunicação das pessoas por meio da imersão no ambiente 
estudado. A pesquisa foi realizada nos meses de janeiro a dezembro de 2013.

Para a proposição do conjunto de indicadores de desempenho da empresa, foram realizadas as seguintes etapas: a) identificação da missão, objetivo e visão das empresas; b) análise das alternativas estratégicas; c) determinação das perspectivas de valor do BSC; d) construção do mapa estratégico; e e) determinação dos indicadores de medição de desempenho agrupados dentro da visão do BSC, entre financeiros, de clientes, de processos e de aprendizado, assegurando-se de que todas as perspectivas tenham sido contempladas.

A soma desses procedimentos permitiu o tratamento e análise dos dados, constituindo-se como uma ferramenta para o desenvolvimento e avanço da gestão estratégica da atividade econômica em estudo. A análise dos dados foi realizada tomando como base todo material coletado em campo, bem como as observações in loco. Os dados foram analisados e interpretados por meio da análise de conteúdo que, segundo Laville e Dionne (1999) e Gil (1999), é uma metodologia que busca a compreensão da construção de significados que o pesquisado exterioriza no seu discurso.

\section{RESULTADO E DISCUSSÃO}

A fazenda tem área total de 396 ha, em que 40\% desta área é arrendada. Suas atividades são a cultura de café com $40 \%$ do faturamento e a pecuária leiteira, representando $60 \%$ do faturamento; daí o foco deste estudo ser na atividade leiteira. A proprietária não reside na fazenda; apesar de ter crescido no meio, tem apenas três anos de experiência no agronegócio. Nesses anos que está na gestão, vários investimentos foram feitos. Um deles, e talvez o mais importante, foi a construção de um free stall, para proporcionar maior conforto para o gado, que entrou em operação ao final do primeiro trimestre de 2014.

Essa propriedade conta com seis funcionários permanentes que lidam diretamente com a pecuária leiteira, um veterinário terceirizado que auxilia na parte zootécnica e um técnico da empresa fornecedora de ração, que presta consultoria nesta área.

O plantel da fazenda é de 164 vacas em lactação da raça holandesa, puras por cruzamento ou puras por origem (PC ou PO) que ficam semi-confinadas. Com a finalidade de melhorar a produção, a compra de animais é frequente. As ordenhas ocorrem duas vezes ao dia e a produção diária chega a 3.200L, uma média de 19,51 litros de leite por vaca em lactação, valor bem superior à média de muitas propriedades da região (Lopes et al., 2015).

Práticas como o pré e pós-dipping são realizadas para a prevenção de doenças no rebanho e, consequentemente, buscando aumentar a qualidade do produto final. A gestora tem o conhecimento sobre os programas de pagamento de qualidade promovido pelos compradores e cooperativas; porém, hoje é feito apenas o controle do peso do produto. Há o interesse, por parte da gestora, em melhorar a qualidade do leite produzido, expandindo o controle para parâmetros como CCS (contagem de células somáticas), índice de gordura, acidez e temperatura, que são utilizados pelas principais cooperativas para atestar a qualidade do leite e recompensá-los financeiramente por isso (PAIXÃO et al., 2014; DEMEU et al., 2015). Não há a preocupação pela fidelização do comprador, uma vez que a produção é vendida para aquele que oferecer o melhor preço.

Na gestão do negócio, não há qualquer tipo de planejamento, seja para investimento em novos equipamentos, aquisições de novas áreas ou um possível aumento das atividades. O único planejamento realizado é para a manutenção das máquinas e equipamentos, ou seja, o suficiente para manter as operações diárias. De acordo com Lopes (2015), o sucesso de uma propriedade leiteira é consequência de um bom planejamento, em seus diversos aspectos e componentes do sistema de produção. 
No que tange aos recursos humanos, o salário pago aos funcionários é superior à média da região e eles não possuem qualquer estímulo por melhora nos resultados. Suas tarefas são divididas de acordo com a capacitação de cada um e, segundo a gestora, esta divisão é bem clara para eles. Apesar de todos saberem o que fazer, não sabem porque fazem, pois, os objetivos principais da propriedade não são transmitidos aos colaboradores. Suas atividades são desenvolvidas de forma rotineira e sem o conhecimento da finalidade de suas ações. Muito disso pode ser atribuída à falta de reuniões entre gestor e colaboradores. Para Marques (2012), a comunicação estruturada deve fazer parte do trabalho do líder e quando há uma correta estruturação, visualização e execução de reuniões, é possível perceber um aumento da eficácia e da eficiência na resolução de problemas.

No setor financeiro, não há qualquer registro formal da entrada e saída de recursos. Sabe-se apenas o montante final de cada atividade pelo que é recebido e não pelo controle do que foi vendido. Para fazer investimentos, o cálculo da necessidade de recursos, do tempo a ser gasto e da viabilidade são realizados de forma empírica. Quando há alguma necessidade de caixa, utiliza-se da venda de animais para gerar recursos. A gestão dos recursos dentro de uma organização é tão importante que o seu controle deve ser realizado por meio de uma ferramenta chamada fluxo de caixa. Assaf Neto (2009) afirma que o fluxo de caixa além, de ser uma ferramenta de controle de entrada e saída de recursos, é também uma ferramenta de fácil compreensão dos dados, o que facilita a tomada de decisão por parte do gestor.

Tendo as entrevistas in loco como ponto de partida, foi possível identificar os pontos fortes destacados pela gestora. Segundo ela, a localização da fazenda é um ponto forte, pois a fazenda fica apenas a dois quilômetros do centro urbano mais próximo, facilitando, assim, o acesso do caminhão do laticínio e o seu acesso às facilidades da cidade, condições que ajudam na redução frete e dos gastos com combustível, reduzindo o custo operacional efetivo e, segundo Lopes et al. (2012), contribui no aumento da rentabilidade. Outro ponto forte destacado foi a sua infraestrutura disponível, principalmente a sala de ordenha e o free stall, que são estruturas fundamentais que auxiliam na manutenção da higiene e no conforto do animal, o que acaba por influenciar na qualidade final do produto, proporcionando o recebimento de bonificações (PAIXÃO et al., 2014; DEMEU et al., 2015) e também na sua quantidade. Segundo Lopes et al. (2006), a otimização da infraestrutura, pelo aumento da escala de produção, até determinados níveis, resultará na redução do custo médio com depreciação, com consequente aumento na lucratividade.

O terceiro ponto forte apresentado é a fonte de água potável que é utilizada nas atividades da propriedade. É de fundamental importância que a água usada na atividade leiteira seja potável, com baixa contaminação por coliformes e outros gêneros bacterianos como Pseudomonas e Bacillus (COUSIN; BRAMLEY, 1981). O leite pode ser contaminado quando entra em contato com a superfície do equipamento e/ou utensílios de ordenha, assim como no próprio tanque de refrigeração do leite. A contagem bacteriana total do leite pode aumentar significativamente quando em contato com equipamentos nos quais a limpeza e sanitização são deficientes, pois os microrganismos proliferam nos resíduos de leite presentes em recipientes, borrachas, junções e qualquer outro local onde ocorra acúmulo de resíduos de leite. Além disso, de acordo com Menezes et al. (2014), a higienização dos tetos com água não potável pode aumentar a contaminação microbiana do teto, alterando a qualidade do leite.

Em relação aos pontos fracos, foi apontada a ausência de controles para acompanhar não só a situação financeira, mas também a qualidade do leite produzido e a saúde do rebanho, o que, segundo Ferrazza et al. (2015a), são imprescindíveis como ferramenta de rotina gerencial e também no planejamento e tomadas de decisão. Outro ponto fraco apresentado foi a mão de obra pouco especializada, fato que tem acarretado em desperdício de insumos e até mesmo da produção diária por falta de conhecimento dos funcionários durante a ordenha e o armazenamento do leite. Ferrazza et al. (2015) 
salientaram que um baixo nível de investimento em mão de obra afeta diretamente a produtividade. Maia et al. (2010) apontaram que a baixa escolaridade dos funcionários pode afetar negativamente o processo de melhoria na produção, tendo em vista que a baixa qualificação e baixo conhecimento não permitem, por parte dos funcionários, o uso de novas tecnologias. O terceiro ponto fraco, apresentado pela proprietária, foi sua gestão feita de forma reativa, ou seja, não há um planejamento para a realização das atividades, fato este que, segundo Silva (2015), seria fundamental para conhecer e delinear os passos seguintes como forma de se obter uma vantagem competitiva em relação aos seus concorrentes.

Apresentados os pontos fortes e fracos, a gestora, em parceria com os pesquisadores, definiu os seguintes pontos que são chave para a definição da missão: implantação de melhorias no que diz respeito à gestão, principalmente no que tange ao planejamento das ações e realizar ações para se alcançar a qualidade dos produtos e melhoria dos recursos humanos. Desta forma, a missão definida em conjunto foi: "Procurar estar sempre em sintonia com as melhores práticas aplicáveis a gestão da propriedade, aos recursos humanos e sistema de produção, afim de proporcionar qualidade superior no que produz." A elaboração da missão, segundo Tachizawa e Rezende (2002), é fundamental, pois ela é a razão de ser da organização, além de demonstrar qual a sua função social.

Se por um lado a missão descreve a razão de ser da organização, é necessário descrever como ela pretende alcançar seus objetivos estratégicos; para isso, a visão estratégica deve ser criada. Segundo Decourt et al. (2015), a visão é uma descrição de onde a organização pretende estar no médio e longo prazo; que para ele, são aproximadamente cinco anos. Para esta propriedade, a visão elaborada foi: "Ser reconhecida na região pela gestão eficaz e pela qualidade dos seus produtos".

Ainda segundo Decourt et al. (2015), após apresentado onde a empresa espera estar, é fundamental destacar com base em quais princípios éticos ela pretende fazer isso. Neste quesito, a proprietária destacou como os principais valores para uma gestão eficiente a qualidade dos produtos vendidos, o respeito aos funcionários e clientes, a preocupação com bem-estar dos animais e a eficiência na produção.

Segundo Wheelen (1994), a estratégia é a elaboração de um plano mestre que deve mostrar como a empresa irá alcançar sua missão e seus objetivos, com vistas a maximizar as vantagens e minimizar as desvantagens. Para a propriedade em questão, a formulação da estratégia leva em consideração o desejo da gestora de aplicar as melhores práticas de gestão, além de proporcionar qualidade nos produtos finais. Com base nisso, os pontos fundamentais para que a propriedade alcance o sucesso são: Investir em capacitação dos recursos humanos disponíveis (gestor e colaboradores) pois, segundo Paixão et al. (2014), apesar do investimento em capacitação da mão de obra ser pequeno, via Serviço Nacional de Aprendizagem Rural (SENAR), o reflexo destes treinamentos, principalmente do ordenhador, são expressivos na qualidade do leite produzido e manejo dos animais. Outro ponto fundamental é o investimento em tecnologias que tornem a gestão mais eficaz e ágil, principalmente no que diz respeito à tomada de decisão. De acordo com Lopes (1997), a tecnologia aumenta a produtividade e facilita a vida do pecuarista e trabalhador. Por último, o aumento da qualidade dos produtos vendidos, que, conforme apresentado por Teixeira Júnior et al. (2015), tem impacto direto no preço pago pelos laticínios.

Definidos os pontos fundamentais para o alcance do sucesso, os seus desdobramentos se darão dentro das quatro perspectivas do BSC (financeira, do cliente, dos processos internos, do aprendizado e crescimento) (KAPLAN;NORTON, 1997), por meio dos objetivos em cada uma delas. Segundo Padoveze (2009), apesar de o BSC ter toda uma conotação estratégica, sua atuação tem um foco na área operacional, pois a maioria dos indicadores sugeridos é, na verdade, objetivos e metas de cunho operacional, sem se esquecer, do aspecto sistêmico que rege todo seu conceito e que é divido nas quatro perspectivas.

Em relação à perspectiva financeira, a busca pela maximização dos resultados é o ponto principal desta perspectiva (KAPLAN;NORTON, 1997). Porém, o aumento do lucro depende da redução do custo 
e/ou aumento da receita que por sua vez é influenciada pela quantidade produzida e pelo preço de venda. Esse último, de acordo com Teixeira Júnior et al. (2015) e Lopes et al. (2011), pode ser incrementado se o pecuarista adotar práticas zootécnicas que visam a melhoria da qualidade do leite proporcionando, assim, um diferencial pago pelos clientes como forma de bonificação.

Os objetivos traçados dentro desta perspectiva foram: diminuição do custo médio e aumento do preço pago pelo litro do leite e, para alcançá-los, os indicadores propostos são: Faturamento mensal bruto total (FBT); Custo Total Mensal (CTM); Faturamento mensal bruto do leite (FBL); Custo mensal do leite (CML); Preço de venda do leite (PVL); Participação mensal da renda bruta do leite na renda da atividade $(\mathrm{PRBL})(\mathrm{PRBL}=\mathrm{FBL} / \mathrm{FBT})$.

Em relação à perspectiva do cliente, é importante identificar o que irá criar valor para os clientes/compradores, ou seja, é preciso identificar e atender suas necessidades e desejos (KAPLAN; NORTON, 1997). No mercado de leite, uma das maiores exigências das agroindústrias são por produtos de melhor qualidade e, para isso, torna-se necessária uma adequação dos produtores de leite a esta nova realidade. A exigência se dá devido ao fato de que o leite cru com pior qualidade, como aquele com contagem de células somáticas elevada, devido ao quadro de mastite, possui maior concentração de plasmina (uma enzima a qual degrada as proteínas do leite); e, devido à estabilidade térmica desta enzima, a vida de prateleira do leite pasteurizado e produtos lácteos ficam comprometidos (AULDIST; HUBBLE, 1998). Além disso, há ainda o efeito negativo no rendimento na fabricação de queijos (BARBANO et al., 1991; POLITIS; NG-KWAI-HANG 1988). Não há a preocupação pela fidelização do comprador, uma vez que a produção é vendida para aquele que oferecer o melhor preço. Teixeira Júnior et al. (2015) salientaram que o produtor tem dois caminhos para escolher: ou ele busca produzir um leite de qualidade e se beneficia da bonificação e se mantem competitivo, ou ele permanece com sua produção tradicional e fica fadado a ser excluído do sistema. Para Paixão et al. (2014), algumas ações podem fazer com que melhore a qualidade do leite vendido: a melhoria no manejo, higiene na ordenha, sanidade da glândula mamária, manutenção e desinfecção dos equipamentos, entre outras.

Com base nisso, os objetivos estratégicos desta perspectiva estão ligados à qualidade do leite e a satisfação do cliente. Os indicadores para esta perspectiva são: Teor de proteína no leite (TPL); Teor de gordura no leite (TGL); Contagem de células somáticas (CCS); Contagem bacteriana total (CBT) e Reclamações dos clientes/compradores (RC). A aferição destes indicadores deve ser realizada mensalmente.

A perspectiva dos processos internos apresenta o que deve ser feito dentro da organização para satisfazer às expectativas dos clientes-alvo (KAPLAN; NORTON, 1997) e, para a propriedade em estudo, o intuito é otimizar a produção na fazenda por meio de processos mais eficazes, isto por que, conforme Paixão et al. (2014), processos internos que cuidam para evitar a contaminação do leite devem ser tomados desde a ordenha até o beneficiamento e são obtidos por meio de boas práticas agropecuárias. Neste sentido, os objetivos estratégicos sobre essa perspectiva são: desenvolver procedimentos eficazes à higienização do rebanho e dos equipamentos utilizados na ordenha.

Para esta perspectiva, os indicadores propostos têm como finalidade melhorar a saúde do animal com foco principalmente no processo de ordenha que, segundo Santana et al. (2004), é o ponto onde há um alto índice de contaminação do animal e principalmente do leite. Os indicadores propostos são: Índice de ocorrências sanitárias; Taxa de fecundidade; Taxa de mortalidade; Custo alimentar por kg de leite; Produção de leite diária e Produção de leite por vaca por dia. A exceção dos dois últimos indicadores, as medições serão mensais.

No que tange à perspectiva do aprendizado e crescimento, os indicadores devem ser orientados constantemente para o crescimento profissional dos recursos humanos (gestora e funcionários) e satisfação 
dos funcionários. Conforme Taffarel (2013), os funcionários e ordenhadores bem treinados terão mais cuidado na manutenção das ordenhadeiras, bem como farão sua higienização, evitando a perda de qualidade e até mesmo de toda a produção. Esta perspectiva deve contemplar também o investimento em novas tecnologias, inclusive as que se referem à gestão.

Com base nisso, capacitar os recursos humanos a implantar técnicas modernas de gestão e manejo, bem como utilizar softwares para controle e gestão, além de estimulá-los ao desenvolvimento pessoal por meio de recompensas são os objetivos da propriedade dentro desta perspectiva. Para atender a estes objetivos, os indicadores propostos são: Produção mensal por quantidade de colaboradores; Investimento mensal em treinamento; Investimento mensal em tecnologia; Satisfação dos colaboradores. A exceção do último indicador, todos os outros deverão ser medidos mensalmente. A satisfação dos colaboradores deverá ser aferida por uma pesquisa semestral com os mesmos.

Em resumo, os indicadores de desempenho propostos para as quatro perspectivas estão descritos no Quadro 1 a seguir:

Quadro 1 - Indicadores de desempenho de uma propriedade leiteira de médio porte.

\begin{tabular}{|c|c|}
\hline Perspectiva & Indicadores \\
\hline \multirow{6}{*}{ Financeira } & Faturamento Bruto Mensal Total \\
\hline & Custo mensal total \\
\hline & Faturamento mensal bruto do leite \\
\hline & Custo mensal do leite \\
\hline & Preço de venda do leite \\
\hline & Participação mensal da renda bruta do leite na renda da atividade \\
\hline \multirow{5}{*}{ Do Cliente } & Teor de proteína no leite \\
\hline & Teor de gordura no leite \\
\hline & Contagem de células somáticas \\
\hline & Contagem bacteriana total \\
\hline & Reclamações dos clientes/compradores \\
\hline \multirow{7}{*}{$\begin{array}{l}\text { Dos Processos } \\
\text { Internos }\end{array}$} & Índice de ocorrências sanitárias \\
\hline & Taxa de fecundidade \\
\hline & Taxa de mortalidade \\
\hline & Custo alimentar por kg de leite \\
\hline & Consumo de água e energia \\
\hline & Produção de leite diária \\
\hline & Produção de leite por vaca por dia \\
\hline \multirow{4}{*}{$\begin{array}{l}\text { Do Aprendizado e } \\
\text { Crescimento }\end{array}$} & Produção mensal por número de colaboradores \\
\hline & Investimento mensal em treinamento \\
\hline & Investimento mensal em tecnologia \\
\hline & Satisfação dos colaboradores \\
\hline
\end{tabular}

Fonte: Dados da Pesquisa

Diante do exposto, pode-se perceber que há uma relação forte de causa e efeito entre os objetivos e indicadores de cada uma das perspectivas; por exemplo: com a capacitação e satisfação dos funcionários da fazenda é possível obter qualidade nas atividades desenvolvidas internamente, o que acarretará na satisfação dos clientes e sua consequente fidelidade, aumentando, assim, o resultado final, gerando um retorno maior ao capital investido. Kaplan e Norton (1997) descreveram esta relação afirmando que a cadeia de causa e efeito deve permear todas as quatro perspectivas do BSC.

Tendo como base os indicadores das quatro perspectivas listadas (Quadro 1), é possível apresentar o BSC em forma de mapeamento, onde as relações de causa e efeito dos objetivos podem ser mais claramente vistas. Para a propriedade estudada, o mapa estratégico desenvolvido está apresentado na figura 1. 
Crescimento e Inovação

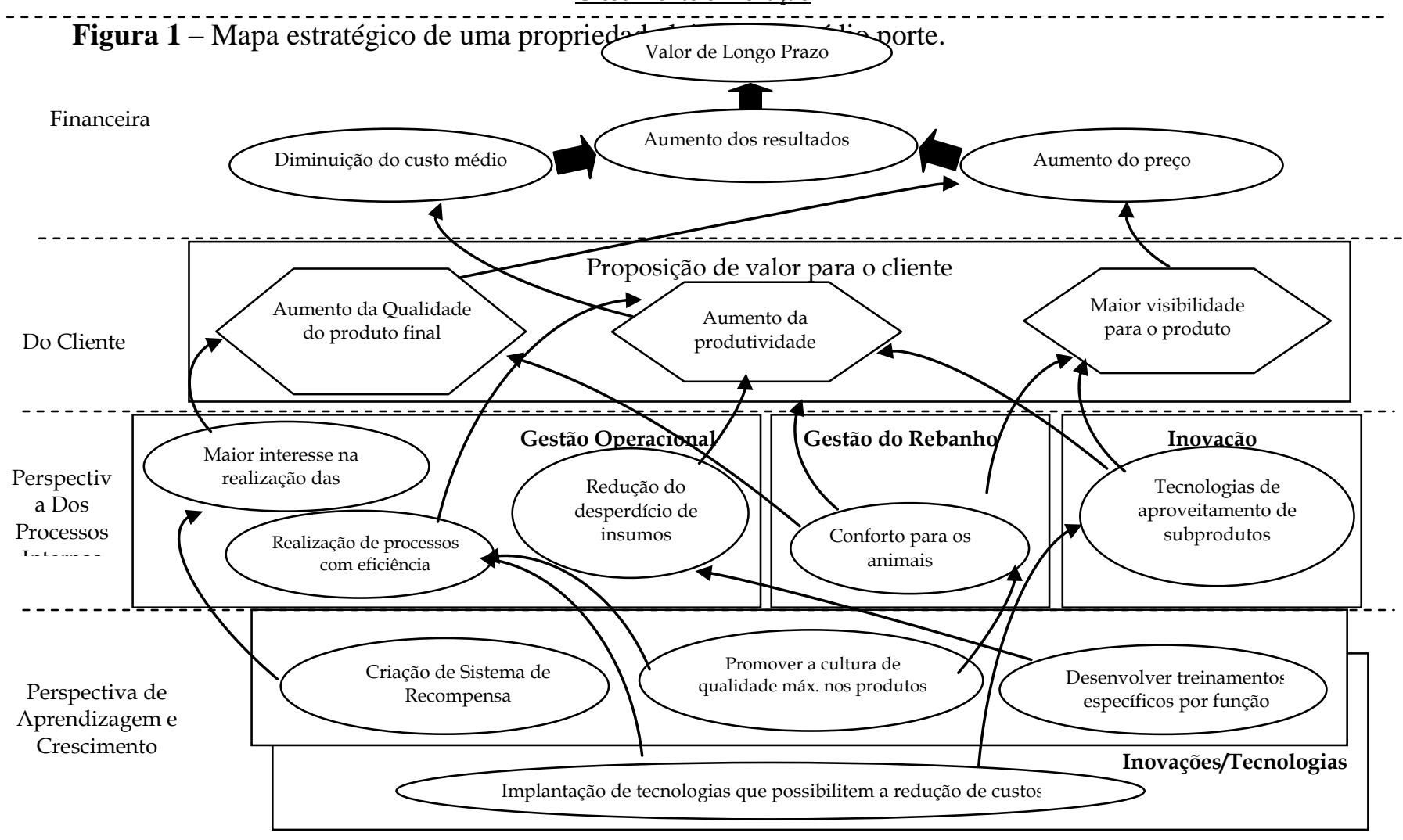

Fonte: Dados da Pesquisa

Para o entendimento desse mapa, sua leitura deve-se iniciar pela perspectiva do aprendizado e crescimento, que está pautada na implantação de tecnologias que possibilitem a redução de custos, como softwares de gestão que auxiliem no gerenciamento da propriedade. Ainda dentro desta perspectiva, a criação de sistemas de motivação para os funcionários e treinamentos, sendo alguns gratuitos, como os promovidos pelo SENAR (PAIXÃO et al., 2014), possibilitará melhoria nos processos internos, seja de ordenha, arraçoamento dos animais, aproveitamento de subprodutos e redução do desperdício, além da adoção medidas higiênico-sanitárias. A realização destas ações levará os funcionários a um maior comprometimento com a operação, além de motivá-los a contribuir com o resultado final da propriedade. Eles terão mais atenção ao desperdício de insumos, realizarão os processos de forma mais eficiente, e a excelência nesses processos irá se traduzir em qualidade final do produto e aumento da produção, o que acarretará em maior visibilidade e rentabilidade para a propriedade.

Essas ações têm impacto no processo financeiro, pois reduzem o custo médio de produção, além de aumentar o preço pago pelos clientes, pois a qualidade é fator preponderante para a decisão de compra e preço pago pelo litro do leite (LOPES et al., 2011). Desta forma, a fazenda conseguirá atingir seu objetivo que é o aumento da rentabilidade.

Conforme mencionado por Kaplan e Norton (1997), o BSC é uma ferramenta que tem por objetivo integrar toda a administração, levando em consideração não só os aspectos financeiros, mas também aqueles voltados aos clientes, aos processos internos e ao crescimento organizacional e aprendizado. Por esse motivo, entende-se que esta ferramenta é capaz de transformar uma diretriz estratégica em uma atividade que envolva toda a organização, implantando, para isso, indicadores de desempenho que irão motivar todos os colaboradores para o alcance do objetivo ora estabelecido. 


\section{CONSIDERAÇÕES FINAIS}

Verificou-se que o modelo de Balanced Scorecard, proposto por Kaplan e Norton, pode ser aplicado a uma propriedade produtora de leite de médio porte; porém, vale destacar que antes de qualquer ação, é preciso que os gestores participem de todo o processo, desde a definição dos objetivos, até a escolha dos indicadores de desempenho, pois é fundamental que eles acreditem na estratégia e desenvolvam a cultura de planejamento estratégico na organização.

Recomenda-se que novos estudos sejam desenvolvidos sobre o modelo Balanced Scorecard nas propriedades produtoras de leite, com o foco em outros aspectos como a aplicação e monitoramento da ferramenta, sendo que o presente estudo buscou trazer a contribuição a respeito da sua aplicabilidade com intuito de melhorar o desempenho da propriedade.

Compreende-se que o BSC é uma ferramenta gerencial que envolve de maneira profunda o capital humano, que é a base do sucesso de qualquer organização, e acredita-se que quanto maior for o envolvimento desses com a metodologia proposta pelo Balanced Scorecard, maior e melhor serão os resultados.

\section{AGRADECIMENTOS}

Os autores agradecem à FAPEMIG e ao CNPq, pelo apoio na realização deste estudo.

\section{REFERÊNCIAS}

ASSAF NETO, A. Finanças Corporativas e Valor. 7 ed. São Paulo: Atlas, 2014. 824p.

AULDIST, M.J.; HUBBLE, I.B. Effects of mastitis on raw milk and dairy products (Review paper). The Australian Journal of Dairy Technology, v.53, p.28-36, 1998.

BARBANO, D. M.; RASMUSSEN, R. R.; LYNCH, J. M. Influence of Milk Somatic Cell Count and Milk Age on Cheese Yield. Jornal of Dairy Science, v74, n. 2, p. 369-388, 1991.

BIGLIARDI, B.; BOTTANI, E. Performance measurement in the food supply chain - a balanced scorecard approach. Facilities, v. 28, n. 5/6, p. 249-260, 2010.

BRYCESON, K. P.; SLAUGHTER, G. Alignment of performance metrics in a multi-enterprise agribusiness: Achieving integrated autonomy? International journal of productivity and performance management, v. 59, n. 4, p. 325-350, 2010.

BRYMAN, A. Research methods and organization studies. London: Unwin Hyman, 1989. 300p.

BYRNE, A.; KELLY, T. The Development and Application of the Balanced Scorecard for the Irish Dairy Farm Manager. Proceedings of the 20th AIAEE Conference, Dublin, Ireland. 2004.

CANZIANI, JRF. Assessoria Administrativa a Produtores Rurais. 2001. 236f. Tese (Doutorado em Ciências) - Escola Superior de Agricultura "Luiz de Queiroz", Universidade de São Paulo, Piracicaba, 2001.

CARDEMIL-KATUNARIC, G.; SHADBOLT, N. The Balanced Scorecard as a spontaneous framework in an agricultural hybrid cooperative under strategic change: A case study in the New Zealand kiwifruit industry. In: World Food and Agribusiness Congress, Buenos Aires, Argentina. 2006. 
COUSIN, M. A.; BRAMLEY, A. J. The microbiology of raw milk. In: ROBINSON, R. K. Dairy microbiology. New York: Applied Science, 1981. v. 1, p. 119-163

DECOURT, F.; NEVES, H. R.; BALDNER, P. R. Planejamento e gestão estratégica. São Paulo, SP: Editora FGV, 2015. 134p.

DEMEU, F. A.et al.Influência da escala de produção no impacto econômico da mastite em rebanhos bovinos leiteiros. Revista Ceres. v.62, n.2. p.167-174. 2015.

DUNN, B.H.; ETHEREDGE, M. Key indicators of success in ranching: a balanced scorecard approach. Range Beef Cow Symposium, Paper 47. University of Nebraska, Lincoln, 2005.

DUNN, B.H.et al. Using the Balanced Scorecard for Ranch Planning and Management: Setting Strategy and Measuring Performance. Manual of South Dakota State University, Texas A\&M University and North Central SARE, p.1-32, 2006.

FERRAZZA, R.et al. Índices de desempenho zootécnico e econômico de sistemas de produção de leite com diferentes tipos de mão de obra. Ciência Animal Brasileira, v. 16, n. 2, p. 193-204, 2015.

FERRAZZA, R.et al. Índices de desempenho zootécnico e econômico de sistemas de produção de leite com diferentes níveis tecnológicos. Semina: Ciências Agrárias, v. 36, n. 1, p. 485-496, 2015 a.

GIL, A. C. Métodos e técnicas de pesquisa social. 5 ed. São Paulo, SP: Atlas, 1999. 200p.

GODINHO, R. F.et al. Gestão empresarial em sistemas de produção de leite na microregião de São João Batista do

Glória/MG. Ciência et Praxis, v. 6, n. 12, p. 39-50, 2014.

JACK, L. The adoption of strategic management accounting tools in agriculture post subsidy reform: a comparative study of practices in the UK, the US, Australia and New Zealand. Chartered Institute of Management Accountants, v. 5, n. 7, p. 1-7, 2009.

KAPLAN, R. S.; NORTON, D. P. A estratégia em ação: balanced scorecard. 21 ed. Rio de Janeiro: Elsevier, 1997. 360p.

LAVILLE, C.; DIONNE, J. A construção do saber: manual de metodologia da pesquisa em ciências humanas. Artmed; UFMG, 1999.

LISSITSA, A. The Balanced Scorecard Implementation in Farm Enterprise - a Case Study from Ukraine. In: CONGRESS, 15. Anais... Campinas SP, Brazil, August 14-19, 2005. International Farm Management Association, 2005.

LOPES, M. A. Informática aplicada à bovinocultura. Jaboticabal: FUNEP, 1997. 82p.

LOPES, M.A.et al. Efeito da escala de produção nos resultados econômicos de sistemas de produção de leite na região de Lavras (MG): um estudo multicasos. Boletim de Indústria Animal. v.63, n.3, p.177-188. 2006.

LOPES, M. A.et al. Influência da contagem de células somáticas no impacto econômico da mastite em rebanhos bovinos leiteiros. Arquivos do Instituto Biológico. v.78, n.4, p.493-499. 2011.

LOPES, M. A.; SANTOS, G. dos; CARVALHO, F. de M. Comparativo de indicadores econômicos da atividade leiteira de sistemas intensivos de produção de leite no Estado de Minas Gerais. Revista Ceres. v.59, n.4, p.458-465. 2012.

LOPES, M.A. et al. The effect of technological levels on profits of milk production systems participating in the "full bucket" program: a multicase study. Semina: ciências agrarias. v.36, n.4, p.2909-2922. 2015. 
LOPES, M. A. Gestão na bovinocultura de leite. Lavras: UFLA. 2015. 97p. (Apostila do Curso de especialização "lato sensu" Curso de Extensão Ambiental para o Desenvolvimento Sustentável).

MAIA, M. B. R. et al. Assistência técnica e extensão rural aos produtores de economia familiar na cadeia produtiva do agronegócio de leite no estado de Rondônia. In: CONGRESSO DA SOCIEDADE BRASILEIRA DE ECONOMIA E SOCIOLOGIA RURAL / SOBER, 48. Anais... Campo Grande, 25 -28 de Julho, 2010.

MARQUES, A. F. S. Envolvimento dos colaboradores no processo de melhoria contínua. 2012. 129 f. Dissertação (Mestrado em Engenharia e Gestão Industrial) Escola de Engenharia da Universidade do Minho, Braga, Portugal, 2012

MENEZES,M. F. C. et al. Microbiota e conservação do leite, Revista Eletrônica em Gestão, Educação e Tecnologia Ambiental, v.18, p. 76-89, 2014.

NOELL, C.; LUND, M. The Balanced Scorecard (BSC) for Danish Farms-Vague Framework or Functional Instrument?. In: FARM MANAGEMENT. NJF Seminar No. 345. Proceedings... Norwegian Agricultural Economics Research Institute, 2002. p. 2-4.

OAIGEN, R. P.et al. Melhoria organizacional na produção de bezerros de corte a partir dos centros de custos. Revista Brasileira de Zootecnia, v. 37, n. 7, p. 580-587, 2008.

PADOVEZE, C. L. Controladoria estratégica e operacional: conceitos, estrutura, aplicação. 2. ed. São Paulo: Pioneira Thomson Learning, 2009

PAIXÃO, M.G. LOPES, M. A.; PINTO, S.M; ABREU, L. R. Impacto econômico da implantação das boas práticas agropecuárias relacionadas à qualidade do leite. Revista Ceres. Viçosa, v. 61, n. 5, p. 612621, set/out, 2014.

PHILLIPS, J. C.; PETERSON, H. C. Strategic planning and firm performance: a proposed theoretical model for small agribusiness firms. Michigan State University, Department of Agricultural, Food, and Resource Economics, 1999.

POLITIS, I.; NG-KWAI-HANG, K. F. Association between somatic cell count of milk and cheeseyielding capacity. Jornal of Dairy Science, v.71, n. 7, p. 1720-1727, 1988.

ROCHA, L. E. V.; LEITE, W. T. A. Transformações recentes do agronegócio mineiro: Uma análise de indicadores de comércio exterior no período de 1996 a 2006. Revista de Economia e Agronegócios, Viçosa, vol. 5, n. 3, p.425-452.

SALOMON, D. V. Como fazer uma monografia. 9 ed. São Paulo: Martins Fontes, 1999. 294p.

SANTANA, E. H. W.et al. Contaminação do leite em diferentes pontos do processo de produção: I. Microrganismos aeróbios mesófilos e psicrotróficos. Semina: Ciências Agrárias, v. 22, n. 2, p. 145-154, 2004.

SHADBOLT, N. M. The Balanced Scorecard: A Strategic Management Tool for Ranchers. Rangelands, v. 29, n. 2, p. 4-9, 2007..

SILVA, D. B.; SILVA PEREIRA, M.; SPROESSER, R. L. O planejamento estratégico como ferramenta para obter vantagem competitiva no agronegócio. Anais do Encontro Científico de Administração, Economia e Contabilidade, v. 1, n. 1, 2015.

SPECTOR, N. Manual para a redação de teses, dissertações e projetos de pesquisa. 2 ed. Rio de Janeiro, RJ: Guanabara Koogan, 2002. 150p. 
TACHIZAWA, T.; REZENDE, W. Estratégia Empresarial. Tendência e Desafios: Um enfoque na realidade brasileira. São Paulo: Makron Books, 2002. 193p.

TAFFAREL, L. E. et al. Manutenção de ordenhadeiras em propriedades familiares do oeste do Paraná. UDESC em Ação, v. 6, n. 1, 2013.

TEIXEIRA JÚNIOR, F. E. P; LOPES, M. A.; RUAS, J. R. M. Effect of payment for milk quality on the profitability of dairy farming. Revista do Instituto de Laticínios Cândido Tostes, v. 70, n. 1, p. 24-34, 2015.

TRIVIÑOS, A. N. S. Introdução à pesquisa em ciências sociais: a pesquisa qualitativa em educação. São Paulo: Atlas, 1987, 176p.

WHEELEN, T. H. Descriptive model of strategic management. In: DE WIT, Bob \& MEYER, Ron: Strategy: process, content, context - an international perspective. St. Paul/USA: West Publishing, 1994. 46p.

YIN, R. K. The case study crisis: Some answers. Administrative science quarterly, p. 58-65, 1981.

YIN, R. K. Case study research: Design and methods. Sage publications, 2013, 181p. 
